\title{
Interjecciones, onomatopeyas y ¿sonidos inarticulados? Una reflexión desde la perspectiva de categorización cognitiva
}

\author{
Lucía Bernardi*
}

\begin{abstract}
Resumo
Este artículo estudia el espacio de categorización de las interjecciones propias frente a las onomatopeyas y los sonidos inarticulados, desde la teoría de los prototipos (BERLIN; KAY, 1969; ROSCH, 1973; KLEIBER, 1995). Los datos provienen de los corpora CREA, Davies, del diario El Día, Argentina y páginas de internet. Se examinan las unidades 'ay', 'ah', 'oh', 'ja', 'bua', 'brrr', 'agg'. A partir del análisis, se percibe que las interjecciones poseen su propio espacio de categorización distinto del espacio de los otros elementos abordados, aunque comparten el rasgo de la expresividad. La diferencia reside en que las interjecciones indagadas dan cuenta de la actitud del hablante. Se postula que en la lengua existen, al menos, el sistema de las categorías gramaticales, al que pertenecen las interjecciones y el sistema de categorías expresivas, al que pertenecen onomatopeyas y sonidos inarticulados. Las interjecciones se ubican en el borde del sistema de las categorías gramaticales, manteniendo un vínculo con las categorías del sistema expresivo y se constituyen en pasaje y eslabón entre los dos sistemas.

Palabras clave: Interjección. Onomatopeya. Sonido inarticulado. Teoría de los prototipos. Categorización.
\end{abstract}

\section{Introducción}

Las interjecciones, onomatopeyas y sonidos inarticulados son elementos que han sido vinculados por los estudiosos del lenguaje desde hace siglos. Así, el gramático español Gonzalo Correas en su Arte de la lengua española castellana (1626) considera dentro de las interjecciones lo que denomina voces de animales, por ejemplo, “¡mu! del buey, ¡cra, cra! del cuervo, ¡bé! de la cabra y de la oveja” (CORREAS, 1903, p. 225). Asimismo, incluye en la clase de las interjecciones

* Instituto de Investigaciones en Humanidades y Ciencias Sociales (FAHCE-Conicet). Centro de Estudios e Investigaciones Lingüísticas. Facultad de Humanidades y Ciencias de la Educación. Universidad Nacional de La Plata. Becaria UNLP. 
elementos tales como '¡zis, zas!', que indican 'golpes'. De esta manera, se puede observar que para Correas las onomatopeyas son parte de las interjecciones.

En el siglo XX, Manuel Seco tampoco distingue entre interjecciones y onomatopeyas. En este sentido afirma:

[...] la interjección, aunque no desempeña ningún papel en la oración, está agregada a ella y le añade sus contenidos expresivos. Pero en otros casos la interjección se presenta desempeñando ella misma, por sí sola, el papel de una oración [...] En otros casos, por último, es simple transcripción de un ruido cualquiera por medio de los fonemas (tal como se ve, por ejemplo, en las historietas de los tebeos): iguau!, ¡crac!, iglub!

(SECO, 1999, p. 310).

En el final de la cita anterior, el autor coloca las onomatopeyas, caracterizadas como "transcripción de un ruido cualquiera por medio de los fonemas", en la clase de las interjecciones.

Por su parte, Emilio Alarcos Llorach agrupa las interjecciones en onomatopéyicas, apelativas y sintomáticas. A las primeras les atribuye una capacidad mimética, de adaptación fonemática de ruidos o acciones y con "significante expresivo" (LLORACH, 1994, p. 241). Los ejemplos que propone el gramático son entre otros 'rin', 'pum', 'plas', 'paf'.

En tanto, Julia María Fernández Cuesta (1990) en su estudio sobre los cómics propone que sonidos inarticulados tales como 'grrr!', 'tch!', 'grmphff ' son interjecciones menos lexicalizadas que 'hey!', por ejemplo. Además, incluye en las interjecciones onomatopeyas del tipo 'snap!'. De esta manera, se ve cómo la autora asimila interjecciones, onomatopeyas y sonidos inarticulados.

En la posición opuesta, se ubica Ángel Alonso-Cortés (1999), quien destaca las diferencias entre onomatopeyas, sonidos inarticulados e interjecciones. Así, sostiene que una diferencia sustancial entre las interjecciones y las onomatopeyas reside en que las primeras poseen una función ilocutiva y las segundas una función representativa o imitativa. También excluye explícitamente de la clase de las interjecciones los denominados sonidos inarticulados 'brrr' y 'aggg'.

María Ángeles Torres Sánchez y José Luis Berbeira Gardón (2003), en el marco de la teoría de la relevancia (SPERBER; WILSON, 1986), formulan un conjunto de características que distinguen las interjecciones de las onomatopeyas. 
Mientras que aquellas no contribuyen al valor veritativo de la proposición y codifican información procedimental, las últimas son parte de la proposición y codifican información conceptual. No obstante, reconocen que estos dos elementos comparten la codificación de un contenido subjetivo.

María Jesús López Bobo (2002) retoma las consideraciones de Alonso-Cortés y deja fuera de las interjecciones los sonidos inarticulados y las onomatopeyas, señalando que las primeras dan cuenta de la actitud del emisor; en cambio, las onomatopeyas poseen una función representativa. A pesar de lo anterior, la lingüista hace la salvedad de que existen onomatopeyas que pueden perder su valor referencial dominante y devenir en interjecciones por presentar un valor modalexpresivo, como es el caso de 'ipum!', que en algunos contextos puede perder su contenido referencial. Esta cuestión se trata nuevamente en Cueto Vallverdú y López Bobo (2003).

En este breve, recorrido se puede observar las controversias de clasificación que generan las unidades verbales que estudiamos: por un lado, están aquellos que las homologan y las incluyen en una única categoría; por el otro, se encuentran los que prefieren analizarlas como fenómenos separados. Desde la lingüística cognitiva y más precisamente desde la teoría de los prototipos y del nivel básico se puede obtener una respuesta no tan tajante. Algo que ya intuía López Bobo en su obra, esto es, no son elementos con idénticos comportamientos y rasgos, pero tampoco son absolutamente extraños unos respecto de otros.

\section{Marco teórico}

En este trabajo proponemos estudiar las interjecciones, onomatopeyas y sonidos inarticulados desde las teorías de los prototipos y del nivel básico (BERLIN; KAY, 1969; ROSCH, 1973; LAKOFF, 1987; KLEIBER, 1995). La elección teórica encuentra su justificación en que estas unidades son elementos heterogéneos, difíciles de integrar a la clasificación de categorías de la lengua. Por lo tanto, es necesario abordarlas en un marco de categorización alternativa al de la categorización clásica. Mientras que esta última se caracteriza por establecer categorías con límites definidos, esto es, son discretas, cada uno de sus miembros posee propiedades necesarias y suficientes y tienen el mismo estatus de pertenencia a su categoría; la categorización cognitivista, en cambio, propone un espacio de 
categorización en donde los límites entre las categorías son difusos, se definen por haces de rasgos, no por condiciones necesarias y suficientes; y los miembros presentan grados de pertenencia a la categoría, es decir, existen miembros prototípicos y miembros periféricos. Así, George Kleiber expone:

Esta nueva concepción está basada en las tesis siguientes:

1. La categoría tiene una estructura interna prototípica;

2. El grado de ejemplaridad de un individuo se corresponde con su grado de pertenencia a la categoría;

3. Los límites de las categorías o de los conceptos son borrosos;

4. Los miembros de una categoría no presentan propiedades comunes en todos los miembros; una semejanza de familia es lo que permite agruparlos en el mismo conjunto.

5. La pertenencia de un individuo a una categoría se establece con arreglo a su grado de similitud con el prototipo correspondiente.

6. La pertenencia no se realiza de manera analítica, sino de forma global.

(KLEIBER, 1995, p. 51)

Más allá de que estos principios de la categorización cognitiva corresponden a la versión estándar de la teoría de los prototipos ${ }^{1}$ y de las críticas que recibe (por ejemplo de Kleiber) se presenta operativa para el análisis de la interjecciones, dado que "la definición por haces de rasgos puede ofrecer una explicación de la interjección más completa e integrada en el sistema gramatical de las categorías que la descripción tradicional". (CUENCA; HILFERTY, 1999, p. 61). Además, las dos dimensiones que formula la categorización cognitivista, horizontal y vertical, habilitan una descripción y explicación más ajustada de las unidades que nos proponemos estudiar en el presente trabajo. La teoría de los prototipos permite establecer la dimensión horizontal de la categorización, ya que distingue entre prototipo y periferia. En tanto, la teoría del nivel básico constituye la dimensión vertical de la categorización, dado que posibilita dar cuenta de la estructuración jerárquica de las categorías, atendiendo a una relación inclusiva. En este sentido, se propone que la organización de las categorías se realiza en tres niveles: el nivel superordinado, el nivel básico y el nivel subordinado. Es el nivel básico el que se

1 Cabe destacar que en la versión ampliada de la teoría de los prototipos solo se conservan dos principios: las categorías no pueden ser definidas por condiciones necesarias y suficientes; y los miembros se agrupan por semejanza de familia. A pesar de esta reformulación propuesta por sus propios creadores (Rosch y su grupo de investigadores), Lakoff sostiene que la versión estándar continúa vigente (KLEIBER, 1995, p. 46). 
corresponde con el prototipo. Los elementos de este nivel son identificados con mayor rapidez, se perciben global y fácilmente. Además, en general, se emplean con alta frecuencia, sus términos en la lengua son breves, se aprenden primero, son fáciles de memorizar y poseen una gran riqueza informativa, exigiendo poco esfuerzo cognitivo. De esta manera, la categorización cognitiva se resuelve en dos ejes, horizontal y vertical.

Cuenca y Hilferty (1999) presentan un análisis posible de la interjección desde la teoría de los prototipos y de la teoría del nivel básico. Los lingüistas parten de la noción de prototipo como la imagen mental que se conforma a partir de la interacción de rasgos o atributos característicos. Además, señalan que lo importante para determinar el mayor o menor grado de pertenencia a una categoría por parte de un miembro es el peso de los rasgos que comparte con el prototipo y no tanto la cantidad de atributos compartidos. Esto último se reviste de importancia, dado que los autores proponen incluir las interjecciones en la categoría de nivel básico, fragmento, que está incluido en el nivel de la supracategoría oracional. De esta última, dependen la oración, que es el prototipo, la cláusula y el fragmento, en el nivel básico. Ahora bien, la cláusula comparte un solo rasgo con la oración: la estructura sujeto-predicado. Por su parte, el fragmento, salvo este rasgo, tiene el resto de los atributos de la oración: autonomía distribucional, unidad prosódica, semántica y comunicativa. No obstante, el atributo de mayor peso, para definir qué es una oración, es la estructura sujeto-predicado. Por lo tanto, el miembro más periférico es el fragmento y no la cláusula, a pesar de la cantidad de rasgos que el primero comparte con el prototipo. Para Cuenca y Hilferty las interjecciones conforman una subcategoría en el nivel subordinado de la categoría marginal fragmento del nivel básico, que depende de la supracategoría oracional. No obstante, no solo la interjección constituye el nivel subordinado del fragmento, sino también el fragmento sintagmático, (por ejemplo, ‘¡Fuego!') y la prooración ('sí'/ 'no'). Los autores al clasificar las interjecciones en propias e impropias consideran que las primeras están más próximas a las prooraciones, dado que ambas expresan valores vinculados con la modalidad y que las segundas se acercan a los fragmentos sintagmáticos, ya que al provenir de otras categorías tales como verbos, sustantivos, etc. tienen un significado más fijo que las propias y presentan mayor complejidad.

Respecto de estas últimas consideraciones nosotros hemos propuesto en trabajos anteriores (BERNARDI, 2012a, 2012b) que el espacio de categorización 
de las interjecciones propias se resuelve también en su interior en miembros prototípicos y periféricos, y que aun lo hacen sus valores modales-expresivos. Por ejemplo, 'ay' es una interjección propia prototípica, en cambio, 'bah' es una interjección propia marginal. Ahora bien, existen valores modales-expresivos de 'ay' más prototípicos como es el de 'dolor' y más periféricos como el de 'súplica'. Se percibe, entonces, que el enfoque cognitivo es el más operativo para abordar el estudio de las interjecciones. En este trabajo, como expusimos más arriba, también proponemos analizar las onomatopeyas y los sonidos inarticulados con las herramientas teórico-metodológicas de la teoría del prototipo y del nivel básico.

\section{Justificación del corpus}

Los corpora informatizados, CREA y Davies, encuentran su razón de empleo no solo en la gran cantidad de formas que registran, 154.279.050 y 100.000.000, respectivamente, sino principalmente en que las palabras aparecen en su contexto original. Además, el CREA permite utilizar criterios de selección para las búsquedas según parámetros cronológicos, temáticos, de medios y geográficos. Esto es importante ya que da la posibilidad de obtener muestras de distintas variedades del español, como por ejemplo, del español rioplatense, que presenta un particular interés para nuestras investigaciones. Así, por ejemplo, los datos consultados para nuestro trabajo han sido filtrados según el español de Argentina. El Davies, por su parte, posee la opción de realizar búsquedas de palabras, frases y construcciones gramaticales según frecuencias de uso. Asimismo, en este corpus, también, se especifica el lugar geográfico de procedencia de las muestras, el medio oral/escrito y se puede seleccionar el rango cronológico desde el siglo XIII hasta el siglo XX. En este artículo empleamos casos del español de Buenos Aires del siglo $\mathrm{XX}$. De esta manera, los dos corpora son herramientas valiosas para el estudio de unidades como las interjecciones, onomatopeyas y sonidos inarticulados, dado que es indispensable analizarlas en su contexto de uso.

Además, utilizamos algunos ejemplos de un corpus propio conformado por muestras obtenidas de la versión digital del diario El Día (www.eldia.com.ar) y páginas de internet, que emplean el español rioplatense. Agregar este corpus es necesario para dar cuenta de formas relativamente nuevas, tales como 'juas', cuyas realizaciones datan de estos últimos años, sobre todo en los hipertextos. 


\section{Análisis del corpus}

En este apartado analizaremos las unidades 'ay', 'ah', 'oh', ‘ja', 'bua', 'brrr' y 'agg', privilegiando las muestras del español rioplatense.

En trabajos anteriores hemos estudiado el comportamiento de las interjecciones propias (BERNARDI, 2010, 2012a, 2012b). Respecto de 'ay' hemos observado que se emplea con una variedad de valores semántico-pragmáticos:

(1) 'Ay'... 'Ay'... qué tengo en el bocho... me parece que me explota... que explota... [...] ¡ay qué dolor! (REAL ACADEMIA ESPAÑOLA: Banco de datos (CREA) [en línea]. Corpus de referencia del español actual. <http://www.rae.es> [25/03/2012]).

(2) En general, los libros ( ‘'Ay', los libros!) sobre maternidad se ocupan poco y nada de múltiples. Los hay específicos sobre lactancia, y muy difundidos, pero no tratan el tema en relación a las madres de más de un bebé, que -como intento reivindicar en este capítulo- también existen. (REAL ACADEMIA ESPAÑOLA: Banco de datos (CREA) [en línea]. Corpus de referencia del español actual. $<$ http://www.rae.es $>[25 / 03 / 2012])$.

(3) Inf.b. - Equis. Y - - - yo decía: “i“Ay', que pesado es!” Y me mortificaba tanto y me hacía la burra como yo diciendo: "No soy la madre de este chico.” ¿No? [risas] Esté... pero como en Pinamar se sabe todo - - - ya sabían que era el... que era hijo mío. Y yo le decía a Alvarito: "Sé prudente, no seas imprudente." “Y van a pescar? Y yo voy con ustedes." "Alvarito, son señores grandes" (DAVIES:M32 B).

(4) Inf.b - ¡'Ay’, qué divertido! (DAVIES:M21 B).

En (1) el valor semántico-pragmático de 'ay' es de 'dolor', en (2) de 'lamento/ queja', en (3) de 'queja' y en (4) de 'placer/gozo'. Se percibe que el 'dolor' es el valor semántico-pragmático prototípico. Este incluye tanto un dolor del ámbito físico como psicológico, que se corresponde con la emoción de lamento, a veces con un matiz de queja. No obstante, otro valor semántico-pragmático que se presenta con una alta frecuencia es el de 'gozo/placer'. Por lo tanto, la interjección 'ay' se realiza en contextos de emociones negativas y positivas. Esto hace que se perciba como una interjección polisémica, que depende del contexto para 
determinar su valor. Pero esta afirmación no significa que 'ay' sea un comodín para dar cuenta de cualquier emoción, sino que hay rutinas de uso, que limitan sus posibles valores, esto es, dichos empleos están codificados en la lengua. Así, mientras que el ‘dolor/lamento' y el 'placer/gozo' son valores prototípicos de 'ay', los valores semántico-pragmático de 'súplica' y 'sorpresa' son marginales, ${ }^{2}$ al menos en el español rioplatense:

(5) Como no pueden impedir estas dinámicas, pretenden volver al universo predigital, haciendo que los bits se comporten como átomos ( $;$ 'ay' Negroponte, sacanos de este entuerto!) (REAL ACADEMIA ESPAÑOLA: Banco de datos (CREA) [en línea]. Corpus de referencia del español actual. $<$ http://www.rae.es $>$ $[13 / 11 / 2010])$.

(6) Mas al llegar, i'ay'!, la planta había crecido nuevamente y para peor, esta vez era más grande y más fuerte. (REAL ACADEMIA ESPAÑOLA: Banco de datos (CREA) [en línea]. Corpus de referencia del español actual. $<$ http://www.rae.es> [13/11/2010]).

Estos ejemplos no abundan en los corpora. En cambio, un empleo frecuente en la variedad de español que estudiamos es la interjección 'ay' con valor de 'acuerdo con el interlocutor', pero siempre que se combine con un elemento afirmativo, por ejemplo 'sí':

(7) Inf.b - ...cuando está por subir una al de... escalón. ¿Vos lo viste a [..........] que... Inf.a - 'Ay, sí sí'. Inf.b - ...que agarra y hace unos movimientos así? Fijáte que... que te... Inf.a - Bueno, además hace... hace teatro, por ahí te hace un poco de teatro y después... Inf.b - Si cuando no lo ves sale corriendo. Inf.a - Sí. Inf.b - Me hacía acordar a lo... Inf.a - Pero sí, sí. Inf.b - Me hacía acordar (DAVIES: M24 B).

2 La tendencia encontrada en los corpora indica que el $40 \%$ de los datos corresponden al valor semántico-pragmático de 'dolor'/'lamento', el 30\% al de 'gozo'/"placer' (incluimos el valor de 'acuerdo con el interlocutor', que tratamos a continuación), $10 \%$ al de 'queja', otro $10 \%$ al de 'crítica' solo un 5\% para el valor de 'sorpresa', $2 \%$ para el de 'súplica' y el restante $3 \%$ vehiculiza valores como el de 'amenaza', aproximadamente. Cabe destacar que estos porcentajes son estimativos, dado que algunas ocurrencias poseen más de un valor semántico-pragmático, por ejemplo, se combinan el 'placer' con la 'burla'. Asimismo, hay ciertos encadenamientos como 'ay + de' que se constituyen como rutinas de uso para transmitir valores de 'lamento' y de 'amenaza'. 
En (7) se ve cómo para tomar el valor de 'acuerdo' la interjección 'ay' debe estar acompañada por 'sí', que en este caso está reduplicada, otorgándole cierto énfasis al enunciado.

Respecto de la posición que ocupa en la estructura, hay una tendencia a colocar la interjección 'ay' en el inicio de esta, aunque potencialmente puede ubicarse en el medio o en el final. No obstante, existe una alta frecuencia de empleo en el comienzo de la cadena. Esto ocurre también con las interjecciones 'ah'/'oh' y es un rasgo que las diferencia sobre todo de las onomatopeyas. Los datos provenientes del corpus CREA corroboran la afirmación anterior, puesto que 'ay' aparece con 337 realizaciones en principio de estructura y 98 en colocación media y final; 'ah', 695 en posición frontal y 85 media o final; 'oh', 274 en el inicio y 84 en el medio o final. La preferencia de los hablantes de español de colocar estas interjecciones propias en posición inicial da cuenta de la importancia que estos le otorgan a lo actitudinal.

Por su parte, 'ah' posee como valores semántico-pragmáticos prototípicos el 'recordar algo' y el 'darse cuenta de algo' (valor evedictivo): ${ }^{3}$

(8) Nahuel: Es más un matrimonio, la verdad. Desde que empezamos a salir no paramos. ¿Cómo dividen las tareas en casa? Catarina: No hay grandes problemas, las repartimos entre los dos, aunque Nahuel es más de agarrar el gato, meterlo en el auto y llevarlo a la veterinaria. A mí me pondría nerviosa esa situación. Nahuel: Cocinamos, hacemos la cama los dos y pasamos la aspiradora los dos. 'Ah', además le pagamos entre los dos a una señora que nos ayuda con las cosas de la casa. Catarina: Y que ahora tiene que venir más, porque yo no estoy tanto en casa. Cuando vienen amigos a comer asado hacemos lo que nosotros llamamos team (equipo). Ordenamos todo de a dos (REAL ACADEMIA ESPAÑOLA: Banco de datos (CREA) [en línea]. Corpus de referencia del español actual. $<$ http://www.rae.es $>[25 / 03 / 2012]$ ).

(9) - Tengo puntitos negros acá.

- Yo también.

- Y yo tengo acá [...]

- 'Ah', esos son lunares. (REAL ACADEMIA ESPAÑOLA: Banco de datos (CREA) [en línea]. Corpus de referencia del español actual. $<$ http://www.rae.es $>$ [25/03/2012]).

3 En los corpora, el $60 \%$ de los casos posee este valor evedictivo. 
En (8) y (9) los hablantes ponen en escena sus procesos cognitivos de 'recordar' en el primer ejemplo y de 'darse cuenta' en el segundo, esto es, de algún modo muestran ante los ojos del receptor sus movimientos mentales.

Esta interjección propia también posee valores semántico-pragmáticos marginales:

(10) Eduardo De La Puente: Señor Presidente, ¿puedo cometer una indiscreción? ¿Qué estaba haciendo en este instante? Menem: Viéndolos a ustedes.

De La Puente: ¿Pero cómo? ¿Cómo...? ¿Cómo está vestido? Pergolini: No, no... Eso es problema de él. Disculpe, ¿le gustó la apertura del programa, todo eso? ¿Le gusta el programa? Menem: Bueno, lo agarré a la mitad...

Pergolini: 'Ah, ah'. ¿Qué vio antes? Menem: Recién llego. (REAL ACADEMIA ESPAÑOLA: Banco de datos (CREA) [en línea]. Corpus de referencia del español actual. $<$ http://www.rae.es> $[14 / 11 / 2010])$.

En (10) se percibe que el valor semántico-pragmático es el de 'poner en evidencia una mentira del interlocutor'. Este no es un valor frecuente en los ejemplos de los corpora. No obstante, se puede ver que detrás de cada uno de estos valores identificados está la actividad cognitiva de 'descubrir'. Así, en (8) se descubre al receptor algo que se mantenía oculto para este por el olvido del emisor, en (9) el emisor descubre para sí mismo algo que ignoraba y en (10) el hablante descubre algo sobre las palabras del otro, en este caso, que no son verdaderas. Sin embargo, como señalamos más arriba, los primeros son valores prototípicos y el último marginal. ${ }^{4}$

En cuanto a la interjección 'oh' se emplea en contextos literarios principalmente en nuestro español rioplatense:

(11) 'Oh' noches, oh compartida y tibia tiniebla, 'oh' el amor que fluye en la sombra como un río secreto, 'oh' aquel momento de la dicha en que cada uno es los dos, 'oh' la inocencia y el candor de la dicha, 'oh' la unión en la que nos perdíamos para perdernos luego en el sueño, 'oh' las primeras claridades del día y yo contemplándola.

4 Quizás habría que postular que son subvalores de 'descubrir' y que estos subvalores son prototípicos y periféricos. De todos modos, se requiere una investigación más profunda. 
(REAL ACADEMIA ESPAÑOLA: Banco de datos (CREA) [en línea]. Corpus de referencia del español actual. $<$ http://www.rae. es $>[13 / 11 / 2010])$.

(12) ¡Dios mío, ‘oh Dios'! Mátame como quieras y cuando quieras, pero no me mates con tanto dolor, con tanto insufrible dolor! O mátame lo antes posible, ipero que nunca a la Ibarguren le dé por roerme los huesos! No lo soportaría, y entonces sí, entonces sí rompería las tablas de tus leyes... (REALACADEMIAESPAÑOLA: Banco de datos (CREA) [en línea]. Corpus de referencia del español actual. <http://www.rae.es> [13/11/2010]).

Se observa que en (11) y en (12) la interjección 'oh' tiene un valor semánticopragmático de 'súplica', pero este valor, que es uno de los prototípicos, se incluye en textos con función poética, tomando un valor 'literario' que subsume al de 'súplica'. De manera análoga sucede con el valor prototípico de 'sorpresa':

(13) Los celtas, cuyo célebre capitán fué Hú hicieron conocer en sus invasiones de los siglos VI y VII antes de nuestra era, las herraduras. Y si nos ocupamos de los ramplones solamente, vemos que en muchísimos tratados, dibujos, etc., aparecen en las herraduras prehistóricas. César en sus ejércitos y también la caballería auxiliar germánica, al batallar contra el celebérrimo Vercingetórix en la toma de Alesia, usaron herraduras en sus cabalgaduras; ellas eran anchas, de bordes redondeados y... ‘joh sorpresa!’ ... ¡tenían ramplones! (REAL ACADEMIA ESPAÑOLA: Banco de datos (CREA) [en línea]. Corpus de referencia del español actual. $<$ http://www.rae. es> [13/11/2010]).

Como se ve en (13) el valor de 'sorpresa' se emplea en un contexto de uso que privilegia el valor literario de la interjección. En el siguiente ejemplo se hace explícito por parte del hablante este valor literario de la interjección 'oh':

(14) nati Pero ¿no te das cuenta? No es por ella que se quiere casar, es por él.

rafael ¡No te metas! ¡No es asunto tuyo!

nati ¿Cómo no le va a doler vender el restaurante? Es que está enfocando todo en tu madre... Él te da el restaurante a cambio de que vos le ayudes.

rafael Terminá con la psicología de café, no podés estar analizando siempre todo. 
nati No estoy analizando, al contrario, vos sos el cerrado. ¿Por qué no abrís un poco más el corazón?

rafael ¡Porque ya lo tengo abierto! Y en serio. Y éste, 'oh’ ironía del destino, de romance no entiende un carajo. Cuando revienta, revienta. Es muy fácil hacerse el poa, hablar del amorrrr, los ángeles, las libélulas, total el que se los termina cargando a todos a caballito es el pelotudo de Rafael.

nati Bueno, está bien, no grites.

(REAL ACADEMIA ESPAÑOLA: Banco de datos (CREA) [en línea]. Corpus de referencia del español actual. $<$ http://www.rae. es> [13/11/2010]).

En (14) se utiliza 'oh' con un valor semántico-pragmático de 'burla/ironía' justamente respecto del lenguaje poético, esto es, uno de los interlocutores usa la interjección 'oh' para imitar el discurso literario. Así, el hablante lo explicita diciendo: “es muy fácil hacerse el poeta”. De esta manera, el valor 'literario' es el prototípico de la interjección propia 'oh', en el español rioplatense actual, valor codificado en esta unidad por sus rutinas de uso en contextos literarios. No obstante, los valores de 'oh', tales como 'súplica', 'sorpresa', 'pena' son evocados cada vez que se emplea dicha interjección propia. Por ejemplo, en (14) más allá de la burla/ironía y de lo literario resuena el valor semántico-pragmático de 'pena' en "oh ironía del destino".

Cabe destacar que las otras interjecciones que estudiamos, 'ay'/‘ah', también se realizan en discurso/textos literarios por su emotividad. Sin embargo, cuando se las utiliza en contextos más informales o coloquiales no poseen un valor semántico-pragmático literario. En cambio, el uso de 'oh' en dichos contextos sí lo mantiene, subrayando un contraste entre literario/no literario como sucede en el ejemplo (14). ${ }^{5}$

Llegados a este punto, se ve que las interjecciones propias estudiadas son elementos de la lengua que codifican diversos valores semántico-pragmáticos vinculados con la actitud del hablante respecto del dictum.

Ahora bien, examinemos qué sucede con las unidades 'ja' y 'bua'. En primer lugar, 'ja’ presenta dudas para su clasificación. ${ }^{6}$ Así, para el Manual de la Nueva gramática de la lengua española (2010) de la Real Academia Española, ‘ja' es

5 Asimismo, la interjección 'oh' se realiza frecuentemente en contextos discursivos religiosos, como las oraciones. Por ejemplo, "Oh Señora mía, oh Madre mía [...]”.

6 Esta cuestión la hemos tratado en una ponencia presentada en el IV Simposio de la Asociación Argentina de Lingüística Cognitiva AALICO, Buenos Aires 5 y 6 de noviembre de 2012. 
una onomatopeya. Sin embargo, el Diccionario de la lengua española, vigésima segunda edición [en línea], la define como una interjección. En tanto, Cueto Vallverdú y López Bobo (2003) también la clasifican como interjección. No obstante, Torres Sánchez y Berbeira Gardón (2003) en el apartado que dedican a las onomatopeyas analizan el siguiente ejemplo: "Entramos y oímos ija, ja, ja!” (2003: 360). Aunque en este caso 'ja' es una onomatopeya, en realidad, este empleo se registra con una baja frecuencia en nuestro español rioplatense. ${ }^{7}$ En cambio, se encuentran con más frecuencia ejemplos en los que ' ja' codifica la actitud del hablante: ${ }^{8}$

(15) No aclares que más no nos subestimas, todos sabemos que lo haces. Amigo mio te ves tan idiota cuando terminas de decir algo y mirás alrededor esperando que te aplaudan. No sabés la paciencia que te tengo. No sabés que yo sé que tu novia te cagó a pedos porque te sentás al lado mío. Tu situación es un cuadro dantesco

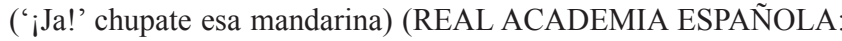
Banco de datos (CREA) [en línea]. Corpus de referencia del español actual. $<$ http://www.rae.es> [30/10/2012]).

(16) petruza

En el gobierno ya se está barajando su nombre para un ministerio... Los de la banda del Gordo Valor no aceptaron porque se asustaron yomelina

\#1 'jajajajajaj' tal cual Petru, (<http://www.eldia.com.ar/edis/20130509/El-autorrobo-siglo-ironizo-blanqueo-Yo-tambien-tengo-ganasinvertir-20130509103132.htm>.09/05/2013).

(17) No, yo siempre en los reportajes hablo de cualquier cosa. Pero por ahí, si salió el nuevo disco me preguntan "¿cuándo es el próximo show?". Y yo siempre digo "no sé". La verdad es que no lo sé. ¡Ah! Sé que tocamos en Cemento el día de Navidad. Con Cemento tengo lazos milenarios. Porque Omar Chaban era de Einstein y nos queremos, aunque es aquel "judío de mierda". Yo le digo a veces: "Omar, vos sos tan judío... que duele... "jja! jja! ¡ja!' (REAL ACADEMIA ESPAÑOLA: Banco de datos (CREA) [en línea]. Corpus de referencia del español actual. $<\mathrm{http}: / / \mathrm{www}$. rae.es> [30/10/2012]).

7 Solo el $5 \%$ de las muestras de 'ja' registra un empleo onomatopéyico .

8 Se trata del $95 \%$ de los casos analizados. 
En (15) 'ja' posee el valor semántico-pragmático de 'burla con enojo', en (16) la repetición de 'ja', cuya grafía termina con 'j', refuerza el valor semánticopragmático de 'alegría empática’ y en (17) ‘ja’ tiene el valor de chiste, atenuando un comentario que de lo contrario sería ofensivo: "Omar vos sos tan judío... que duele..."

Es importante destacar que con las redes sociales, las secciones de comentarios de los diarios digitales, los blogs, entre otros, se han ido especializando distintas formas de ' $\mathrm{ja}$ ':

(18) miexito

Hasta la victoria siempre? CUAL? 'ja ja ja jua jua jua'. 29.08.09 DIA MUNDIAL DEL ABANDONO, el 7777777 a 0000000 no se olvida más. Que mieditooooooo.

(<http://www.eldia.com.ar/edis/20130509/Hasta-victoria-siempredeportes4.htm>. 09/05/2013).

(19) 30/10/2012 - 10:09 |\#6 Marcos_lp

Marcos_lp

Que lastima, hasta la venias rompiendo 'juas juas'

(<http://www.eldia.com.ar/edis/20121030/la-gata-despidio-deltorneo-deportes $0 . h$ tm $>$ ).

(20) edu_paye

pobre CALAMARDO, no le acepta el sistema de EL DIA hacer comentarios como GARPOLFA!!!![...] como no queres que te llamen PATETICO MENTIROSO Y FRAUDULENTO, menos mal que no escribis TODO EL DIA, va, capaz que no lo haces como GARPOLFA O CALAMARDO, pero capaz lo haces como MOSCA DE CORRAL, O TABANITO SERVIL, o MORENITO o PLANCITO ALEGRE no?? 'jejeje'

(<http://www.eldia.com.ar/edis/20130509/Kiciloff-no-motivopara-esperar-devaluacion-20130509120609.htm>. 09/05/2013).

(21) CALAMARDO GARPOLFA OTRO ALIAS.... si lo decis por mi yo QUIZA LADRO (perro el mejor amigo del hombre) vos PICAS y DEJAS VIRUS(mosca tse tse) sigo ladrando o me queres poner BOZAL 'jijijiji', yo tengo palmeta para vos (<http://www.eldia.com.ar/edis/20130509/Kiciloff-no-motivopara-esperar-devaluacion-20130509120609.htm>. 09/05/2013). 
En (18) la burla va in crescendo desde un 'ja' hasta un 'jua', que da cuenta de una burla ostensiva hacia el otro, se corresponde con el gesto de señalar con el dedo. En cambio, en (19) con 'juas' la burla tiene el matiz de lo repentino. En tanto, en (20) 'je' tiene un valor semántico-pragmático de 'burla suspicaz', interpretación reforzada por el contexto verbal que hace referencia a una situación de parcialidad en los comentarios con los sintagmas nominales "mosca de corral", "tabanito servil”, "morenito", "plancito alegre" y en (21) 'ji' la burla es reservada, dado que está enmarcando el encadenamiento "yo tengo palmeta para vos", esto es, un enunciado con cierto grado de agresividad. Estas variedades de 'ja' son difíciles de concebir como onomatopeyas. Así, el encadenamiento 'Entramos y oímos je, je, je/ji, ji, ji' es menos natural que 'Entramos y oímos ja, ja, ja'. Asimismo, parece menos probable de realización la cadena 'Entramos y oímos juas'. Además, como dijimos más arriba este tipo de enunciados con 'ja' son los menos frecuentes. Por lo tanto, la unidad ' $\mathrm{ja}$ ' con sus variedades poseen un contenido modal que predomina por sobre la representación de la risa. De esta manera, se puede sostener que 'ja' es una interjección proveniente de una onomatopeya. No obstante, el hecho de que en ocasiones se pueda emplear todavía como onomatopeya habla de una subjetivación gradual de esta unidad, que se manifiesta también en sus variantes 'je', ‘ji', ‘jua', 'juas'.

Respecto de 'bua' se encuentran pocos ejemplos de su uso:'

(22) [usuario de facebook 1] QUE LA FICCIÓN NO SUPERE A LA REALIDAD...

Es una mañana de enero de 2016.

Mi radio reloj se enciende puntual a las 8 hs con la Mancha de Rolando

a todo volumen en la ahora llamada "Radio del amor y la alegría" (ex

Mitre) [...] Mientras miraba el paisaje de la ciudad, cruzando la Avenida Néstor

Kirchner, por la bocacalle Cristina Corazón, la placita “Él”, el busto al otro Él,

la confitería "el Che", la Boutique "Alto Stalin" y etc. ... se me ocurrió

preguntarme si en aquel OCTUBRE del 2013 hubiera votado

9 Incluso se ha observado que en las redes sociales el empleo de 'bua' alterna con 'sniff'. Este fenómeno es interesante, ya que se registra un uso de interjecciones y onomatopeyas en inglés por parte de los hispanoparlantes. 
distinto, cuál hubiera sido mi presente...

[usuario de facebook 2] Tremendo !!! 'buaaaaaa'

$(<$ https://www.facebook.com $>$ ).

(23) Los tres roles pueden variar como veremos en el ejemplo. No obstante, se mantienen fijos dentro de la estructura de la personalidad. Un ejemplo típico:

ÉL: (Llega de trabajar) ¿Todavía no preparaste la comida?

ELLA: (Se pone a llorar) 'Buah'... siempre me criticas...

(REAL ACADEMIA ESPAÑOLA: Banco de datos (CREA) [en línea]. Corpus de referencia del español actual. $<$ http://www.rae.es $>$ [9/05/2013]).

En (22) 'bua' tiene el valor semántico-pragmático de 'tristeza'. ${ }^{10}$ Pero en (23) 'buah', con la variante de la grafía con ' $h$ ', es ambigua, dado que por un lado, representa el ruido del llanto que se indica en la acotación "(Se pone a llorar)"; y por otro, expresa la actitud del hablante. Esto da cuenta de que 'bua'/‘buah' es una interjección que proviene de una onomatopeya con distintos grados de subjetivación. Sin embargo, en nuestro español rioplatense está codificada la alegría en mayor grado que la tristeza. Mientras que 'ja' se especializa con sus variantes en distintos contenidos modales, ‘bua’/‘buah’ es muy poco utilizada por los hablantes de español rioplatense.

Por último, los elementos 'brrr' y 'agg' se realizan en diferentes contextos que determinan su mayor o menor codificación:

(24) 'Brrr!!!!' Qué Frío!!!

Hemos pasado un invierno muy lluvioso y frío

(<http://unblogdepuntitos.blogspot.com.ar/2010/09/brrr-que-frio. $\mathrm{html}>)$.

(25) Rafael(finge ferocidad) ‘¡Brrr!’ ¡Lo mataría! (Cambia de tono) Lo odio... con su espalda derecha.

(REAL ACADEMIA ESPAÑOLA: Banco de datos (CREA) [en línea]. Corpus de referencia del español actual. $<$ http://www.rae.es $>$ [9/05/2013]).

\section{(26) 'AGG' QUE ASCO}

Ya de por si me desagrada la pepsi común, las fotos de estas pepsis medieron mucho asco, aguante la coca

( $<$ http://www.friki.net/fotos/48083-extranos-sabores-de-pepsi.html $>$ ).

10 Nótese la repetición de la 'a' final, empleada icónicamente para lograr mayor énfasis. 
Se observa que en (25) 'brrr' cuando se combina con la exclamación '¡qué frío!' posee un valor fijo, el de cierto disgusto del hablante respecto del contexto físico. No obstante, en (25) la acotación indica otro valor de 'brrr', el de 'ferocidad' o 'rabia'. Esto significa que 'brrr' como elemento no posee una codificación fija, salvo al ser encadenado con '¡qué frío!' En este caso tiene un contenido modal y no puede ser sustituido por otro sonido. Algo análogo sucede con 'agg'. Así, cuando 'agg' aparece junto a la exclamación ¡qué asco! adquiere un valor fijo de 'repugnancia'. Pero como ocurre con 'brrr', si se realiza en otro contexto su valor es incierto y tiende a ser más un síntoma que un contenido modal.

Estos últimos elementos son más volátiles que 'ja', 'bua' y que las interjecciones propias estudiadas, ya que los contextos en los que se codifican sus rutinas de uso son demasiado limitados. No obstante, interjecciones, onomatopeyas y sonidos inarticulados poseen rasgos en común: la expresividad y la inmediatez del contexto. Asimismo, comparten espacios discursivos en su realización:

(27) En ese momento, Verónica estalló en furia y le contestó: "Yo no fui la que no le abrí la puerta. El padre no le abrió la puerta, que es otra cosa. Estaba Diego, mi mamá y mi papá en Ezeiza. Fue cuando surgió lo del embarazo, porque Dalma quería hablar con el padre sobre mi embarazo".

Gianinna, ni lerda ni perezosa, respondió: 'Jajaja' estoy tentadaaaaaaa!!!!!!!! Te salto la ficha!!!!! 'Shuuufff jajajajaja'. $(<$ http://www.eldia.com.ar/edis/20130605/Gianinna-otro-ataqueTwitter-espectaculos $20 . \mathrm{htm}>$ ).

En (27) 'ja' tiene el contenido modal de la burla y aparece junto con la onomatopeya 'Shuuuufff', que representa el sonido de un enchufe quemado.

\section{Conclusión}

Después de haber recorrido los corpora arribamos a la conclusión de que las interjecciones, las onomatopeyas y los sonidos inarticulados permiten postular, al menos, dos espacios de categorización en la lengua. Uno, el de las categorías gramaticales, al cual pertenecen las interjecciones y otro, el de las categorías expresivas, conformado por onomatopeyas, sonidos inarticulados, entre otros. 
Ahora bien, se ha observado que, por un lado, los tres elementos examinados comparten espacios discursivos, activando los rasgos de expresividad y de inmediatez contextual; $y$ que, por otro, las onomatopeyas y los sonidos inarticulados en determinados contextos pueden subjetivarse y aproximarse en distintos grados a las interjecciones, ya que codifican valores modales. Esto da cuenta de que las interjecciones mantienen un vínculo estrecho con las onomatopeyas y los sonidos inarticulados. Justamente, por eso, las interjecciones se erigen como el eslabón, el pasaje entre los dos sistemas: el gramatical y el expresivo. Las teorías de los prototipos y del nivel básico posibilitan analizar estos pasajes, dado que las fronteras entre categorías y sistemas son borrosas. Asimismo, respecto de las unidades que analizamos, mientras que las interjecciones propias 'ay', 'ah', 'oh' son prototípicas, puesto que más allá de que poseen valores prototípicos y valores marginales, estos remiten a contenidos modales codificados por los contextos de uso, uno de los rasgos distintivos de las interjecciones; las onomatopeyas y los sonidos inarticulados abordados son miembros marginales de sus clases. Por esta razón, pueden con mayor o menor grado acercarse a las interjecciones.

Finalmente, las interjecciones al ubicarse en el borde del sistema gramatical se constituyen en la puerta de entrada que atrae a elementos del sistema expresivo, tal como hemos visto que sucede con la unidad 'ja', por ejemplo. Resta todavía ahondar en el estudio del sistema expresivo: qué elementos lo conforman, además de las onomatopeyas y los sonidos inarticulados, qué relaciones mantienen con el sistema gramatical, cuáles son los miembros prototípicos y cuáles los periféricos, entre otras cuestiones. 


\title{
Interjections, onomatopoeias and inarticulate sounds. A reflection from the perspective of cognitive categorization
}

\begin{abstract}
This paper studies the categorization space of interjections in contrast with onomatopoeias and inarticulate sounds from the perspective of prototype theory (BERLIN; KAY, 1969; ROSCH, 1973; KLEIBER, 1995). The data comes from CREA and Davies corpora, the newspaper El Día, Argentina, and various websites. We examine the units 'ay', 'ah', 'oh', 'ja', 'bua', 'brrr' and 'agg'. The analysis suggests that the interjections have their own categorization space than the space of the other items discussed, although which is different from they share the trait of expressiveness. The difference is that the interjections being investigated convey speaker's attitude. It is postulated that in language there is, at least, the system of grammatical categories to which interjections belong and the expressive system, which entails both inarticulate sounds and onomatopoeias. Interjections are located on the edge of the system of grammatical categories, maintaining a link with the system categories and cand providing an expressive pathway and link between the two systems.
\end{abstract}

Keywords: Interjection. Onomatopoeia. Inarticulate sound. Prototype theory. Categorization.

Referências

ALONSO-CORTÉS, Ángel. Las construcciones exclamativas. La interjección y las expresiones vocativas. In: BOSQUE, Ignacio; DEMONTE, Violeta (Org.). Gramática descriptiva de la lengua española. Madrid: Espasa-Calpe, 1999. 3, p. 3.993-4.050.

BERLIN, Brent y KAY, Paul. Basic Color Terms. Their universality and evolution. Berkeley: University of California Press, 1969.

BERNARDI, Lucía. Las 'interjecciones propias' desde la Teoría de los Prototipos: teoría del lenguaje y conciencia metalingüística. In: CASTEL, Víctor M. y CUBO DE SEVERINO, Liliana (Org.). La renovación de la palabra en el bicentenario de la Argentina. Los colores de la mirada Lingüística Mendoza: Editorial FFyL, UNCuyo, 2010. 24, p. 205-211. 
BERNARDI, Lucía. La interjección ‘Ay': una aproximación a sus usos interjectivos más o menos prototípicos. En: GARCÍA, Adolfo (Org.). Aproximaciones teóricas y empíricas a la lingüística cognitiva. Mar del Plata: Editorial Martin, 2012a. 15, p. 255-266.

BERNARDI, Lucía. Las interjecciones propias: sus valores semánticopragmáticos focales y marginales. Una aproximación desde la teoría de los prototipos. In: GARCÍA, Adolfo; ORELLANO, Verónica; JAICHENCO, Virginia; WAINSELBOIM, Alejandro (Org.). Lenguaje, cognición y cerebro. E-book (volúmenes temáticos de la Sociedad Argentina de Lingüística/ Víctor M. Castel, Mabel Giammatteo \& Alejandro Parini) . Mendoza: Editorial de la Facultad de Filosofía y Letras de la Universidad Nacional de Cuyo, 2012b. 3, p. 67-77.

CORREAS, Gonzalo. Arte grande de la lengua castellana. Madrid: Conde de la Viñaza, Real Academia Española, 1903. Original publicado em 1626.

CUENCA, María Josep; HILFERTY, Joseph. Introducción a la Lingüística Cognitiva. Barcelona: Ariel, 1999.

CUETO VALLVERDÚ, Natalia; LÓPEZ BOBO, María Jesús. La interjección. Semántica y Pragmática. Madrid: Arco/Libros, 2003.

FERNÁNDEZ CUESTA, Julia María. En busca de nuevas grafías para las interjecciones en el comic. In: CONGRESO DE LINGÜÍSTICA APLICADA, 8., 1990, Sevilla. Actas... Sevilla: Asociación Española de Lingüística Aplicada, 1990. p. 181-188.

KLEIBER, Georges. La semántica de los prototipos. Categoría y sentido léxico. Madrid: Visor, 1995.

LAKOFF, George. Women, fire, and dangerous things. What categories reveal about mind. Chicago: University of Chicago Press, 1987.

LLORACH, Emilio Alarcos. Gramática de la lengua española. Madrid: RAE/ Espasa-Calpe, 1994. LÓPEZ BOBO, María Jesús. La interjección. Aspectos gramaticales. Madrid: Arco/Libros, 2002.

REAL ACADEMIA ESPAÑOLA. Nueva gramática de la lengua española. Manual. Buenos Aires: Espasa, 2010.

REAL ACADEMIA ESPAÑOLA, Diccionario de la lengua española. 22. ed. Disponível em: <www.rae.es>. Acesso em: 13 nov. 2010; 14 nov. 2010; 25 mar. 2012; 30 out. 2012; 9 maio 2013. 
ROSCH, Eleanor. On the internal structure of perceptual and semantic categories. In: MOORE, Timothy (Ed.). Cognitive Development and the Acquisition of Language. New York: Academic Press, 1973. p. 111-144.

SECO, Manuel. Gramática esencial de la lengua española. Madrid: EspasaCalpe, 1999.

TORRES SÁNCHEZ, María Ángeles; BERBEIRA GARDÓN, José Luis. Interjección y onomatopeya: bases para una delimitación pragmática. Verba, v. 30, p. 341-366, 2003.

WILSON, Deirdre; SPERBER, Dan. La relevancia. Comunicación y procesos cognitivos. Madrid: Visor, 1986.

\section{Corpora}

CREA, corpus de referencia de la lengua española. Banco de datos de la Real Academia española. Disponível em: <www.rae.es>. Acesso em: 30 out. 2012.

DAVIES, corpus del español. Disponível em: <www.corpusdelespanol.com>. Acesso em: 30 out. 2012.

<www.eldia.com.ar>. Acesso em 30 out. 2012; 9 maio 2013 e 6 jun. 2013.

$<$ http://unblogdepuntitos.blogspot.com.ar/2010/09/brrr-que-frio.html $>$. Acesso em: 19 maio 2013.

$<$ http://www.friki.net/fotos/48083-extranos-sabores-de-pepsi.html>. Acesso em: 19 maio 2013. 
